\title{
Bicalutamide Regimen
}

National Cancer Institute

\section{Source}

National Cancer Institute. Bicalutamide Regimen. NCI Thesaurus. Code C159999.

A chemotherapy regimen consisting of bicalutamide that may be used in the treatment of prostate cancer. 